\title{
ASSESSMENT OF THE EPILEPSY TREATMENT GAP IN TWO CITIES OF SOUTH-EAST OF BRAZIL
}

\author{
Ana Lúcia Andrade Noronha, Lúcia Helena Marques, Moacir Alves Borges, \\ Fernando Cendes, Carlos Alberto Mantovani Guerreiro, Li Li Min
}

\begin{abstract}
Objective: To assess the epilepsy treatment gap in Campinas and São José do Rio Preto, two cities in the State of São Paulo, Brazil. Method: The treatment gap was estimated using the formula n1$\mathrm{n} 2 / \mathrm{n} 1 \times 100$, where $\mathrm{n} 1$ was calculated using $1.86 \%$ prevalence and represented the number of individuals with epilepsy, while $\mathrm{n} 2$ represented the number of people who could be treated with an adult standard dose for a year utilizing the antiepileptic drugs supplied by the public health system. Results: Our estimates revealed that in 2001 , approximately $50 \%$ of the population with epilepsy was treated with the recommended antiepileptic medication. Conclusion: These results suggest that a relevant percentage of patients with epilepsy are not untreated. Further epidemiological studies are needed to investigate the reasons for this treatment gap so that interventions can reduce this gap and improve the quality of life of patients with epilepsy.
\end{abstract}

KEY WORDS: epilepsy, treatment, treatment gap, antiepileptic drugs, stigma.

\begin{abstract}
A lacuna de tratamento em epilepsia em duas cidades do sudeste do Brasil
RESUMO - Objetivo: Estimar a lacuna de tratamento em epilepsia nas cidades de Campinas e São José do Rio Preto, interior do Estado de São Paulo. Método: Estimamos a lacuna de tratamento através da fórmula n1-n2/n1×100, onde se utiliza o número de pessoas com epilepsia, calculado pela prevalência (n1), e a quantidade de pessoas que podem ser tratadas com a dose padrão para adultos das DAEs, distribuídas no período de um ano na localidade (n2). Usamos a prevalência estimada de 1,86\% e consumo de medicação antiepiléptica fornecida pela rede básica de saúde nestas duas cidades. Resultados: Nossas estimativas mostram que somente em torno de metade da população com epilepsia foi tratada em 2001 usando doses preconizadas de medicação antiepiléptica. Conclusão: A nossa estimativa aponta que uma parcela importante dos pacientes com epilepsia não está sendo tratada no nosso meio. Estudos epidemiológicos futuros devem explorar os motivos desta lacuna de tratamento para que intervenções sejam realizadas para melhorar a qualidade de vida dos pacientes com epilepsia.
\end{abstract}

PALAVRAS-CHAVE: epilepsia, tratamento, lacuna de tratamento, drogas antiepilépticas, estigma.

Epilepsy is the most common serious neurological disorder in the world. It has been estimated that $1 \%$ of the world population has some form of epilepsy and the incidence is higher in developing countries ${ }^{1}$. Borges demonstrated that the prevalence of epilepsy in Campinas and São José do Rio Preto is 18.6 for every 1000 inhabitants $^{2}$. This value when extended to the entire country indicates that there are more than three million individuals with some form of epilepsy in Brazil. This high prevalence makes epilepsy a public health problem. Without treatment, patients are unable to work and/or require the constant supervision of a family member, which means added social and econom- ic burden for the family and state ${ }^{3}$. Moreover, an untreated patient with epilepsy requires frequent hospitalization due to the occurrence of seizures or the traumas caused by the seizure or for rehabilitation. Thus, an untreated patient is a burden to the State and to the family.

In addition to the socioeconomic factor, the patient is also affected by an affective-emotional factor because there is a social stigma attached to epilepsy that is due lack of information about this condition ${ }^{4}$. The patients are afraid of socially assuming their epileptic condition fearing social discrimination and stigmatization: they are unable to find employment ${ }^{5,6}$; their personal relationships

Departamento de Neurologia, Faculdade de Ciências Médicas, Universidade Estadual de Campinas (UNICAMP), Campinas SP, Brazil Study Supported by FAPESP (02/11871-8)

Received 28 October 2003, received in final form 3 May 2004. Accepted 5 May 2004.

Dr. Li Li Min - Department of Neurology, Faculty of Medical Sciences, UNICAMP - 13083-970 Campinas SP - Brasil. E-mail: limin@fcm. unicamp.br (http://www.aspebrasil.org) 
are not long lasting 7,8 and they are excluded from society. Therefore many patients do not accept their diagnosis and attribute their seizures to supernatural influences or religious problems ${ }^{8-10}$. They treat them as such or do not undergo any treatment, but keep their condition secret so that they do not suffer discrimination ${ }^{10}$.

In developing countries, besides the socio-cultural problems, there are transport difficulties and extreme poverty. Therefore, a patient who has to travel long distances to receive adequate treatment does not adhere to treatment because it is troublesome and financially difficult. This aspect has been observed by the World Health Organization (WHO) and has been studied by a team that classifies diseases and disabilities that lead to loss of productivity. They concluded that epilepsy is responsible for $0.5 \%$ of the expenditure allotted for worldwide incapacitating diseases and proposed actions that would reduce the incapability of patients with epilepsy ${ }^{11}$.

Hence, epilepsy in Brazil and all other developing countries needs greater attention. This study was conducted with this purpose in mind. We did a simple analysis of one of the aspects of the epilepsy treatment gap in Brazil, studying the antiepileptic drugs (AEDs) consumption. The Brazilian public health system distributes some AEDs with regional differences. The AEDs - carbamazepine, phenytoin and phenobarbital - are distributed in most cities in the State of São Paulo. In some of them, valproic acid is also distributed under a municipal directive. Campinas and São José do Rio Preto (SJRP) are two cities included in the National Demonstration Project on Epilepsy in Brazil ${ }^{12}$ and these four drugs are distributed in these cities. These two cities were analyzed to check if the quantity distributed was sufficient for the estimated population with epilepsy.

Campinas has approximately one million inhabitants and is considered an important industrial as well as commercial center. It has several universities and an extensive public health network consisting of health centers and secondary hospitals. São José do Rio Preto has a population of approximately 340000 inhabitants and also has a teaching hospital attached to the Medical School of São José do Rio Preto as well as a well-structured public health system.

Our objective was to assess the epilepsy treatment gap in Campinas and São José do Rio Preto in 2001.

\section{METHOD}

The indirect method was used to measure the treatment gap of epilepsy by studying the data related to antiepileptic drug availability at the Municipal Health Secretaries in Campinas and São José do Rio Preto during the year 2001. This study received the approval of the Research Ethics Commission, from Faculty of Medical Sciences, UNICAMP.

The following therapeutic doses were defined: carbamazepine (CBZ) - 800 mg/day; phenytoin (PHT) - 300 mg/day; phenobarbital (PB) - 100 mg/day; valproic acid (VA) - 750 $\mathrm{mg} /$ day.

The number of individuals using the AEDs was based on the quantity consumed and the therapeutic dose. For example, we calculated the number of individuals who could be treated with a dose of $800 \mathrm{mg} /$ day utilizing the quantity of carbamazepine distributed to each city.

The population with epilepsy in Campinas (1.000.000 inhabitants) and São José do Rio Preto (340000 inhabitants) was calculated assuming a prevalence of $1.86 \%{ }^{2}$. The treatment gap was obtained applying the formula $\mathrm{n} 1-\mathrm{n} 2 / \mathrm{n} 1 \times 100$, where $\mathrm{n} 1$ is the number of individuals with epilepsy calculated according to the prevalence and $\mathrm{n} 2$ is the number of individuals with epilepsy that could be treated with a standard adult dose of AEDs for a year in that region ${ }^{13}$.

\section{RESULTS}

We estimated an population with epilepsy of 18600 individuals in Campinas and 6324 in Sao José do Rio Preto, but the number of individuals

Table. An estimate of the number of patients using AEDS during the year 2001.

\begin{tabular}{lccccc}
\hline City & $\begin{array}{c}\text { Total } \\
\text { N patients } \\
(\%)\end{array}$ & $\begin{array}{c}\text { CBZ } \\
\text { N patients } \\
(\%)\end{array}$ & $\begin{array}{c}\text { PHT } \\
\text { N patients } \\
(\%)\end{array}$ & $\begin{array}{c}\text { PB } \\
\text { N patients } \\
(\%)\end{array}$ & $\begin{array}{c}\text { VA patients } \\
(\%)\end{array}$ \\
\hline Campinas & 8,182 & 3,809 & 1,024 & 1,856 & 1,493 \\
& $(44)^{*}$ & $(47)$ & $(12)$ & $(23)$ & $(18)$ \\
São José do Rio Preto & 2,591 & 706 & 451 & 1331 & 103 \\
& $(41)^{*}$ & $(28)$ & $(17)$ & $(51)$ & $(4)$ \\
\hline
\end{tabular}

*percentage of population with epilepsy estimated in the city. CBZ, carbamazepine; PHT, phenytoinl; PB, phenobarbital; AV, valproic acid. 
utilizing antiepileptic drugs during 2001 was 8182 in Campinas and 2591 in São José do Rio Preto.

The Table demonstrates the total number of patients treated with each of the AEDs during 2001. A tendency to use carbamazepine was observed in Campinas (47\%), while in SJRP there was greater tendency to use phenobarbital (51\%). Another observation was that valproic acid was less used in SJRP (4\%) than in Campinas (18\%). After calculating the estimated number of individuals with epilepsy and the quantity of medication distributed in each city, the treatment gap in Campinas was found to be $56 \%$ and in SJRP it was $59 \%$.

\section{DISCUSSION}

Epilepsy is a condition that involves high psycho-socio-economic costs ${ }^{3}$. This expenditure is largely due to the fact that the disorder is not treated. However, effective treatment for epilepsy does exist, the only problem is that this treatment may not be available for all individuals with epilepsy as suggested by an analysis of the data in Campinas and São José do Rio Preto.

Epilepsy treatment in Campinas and São José do Rio Preto differed in relation to the preference shown for certain AEDs. The reason for this difference should be investigated as it may indicate if the control of seizures in a population is better with a certain drug, which drugs can be better utilized and if differences in the population are responsible for the choice of the drug.

Our estimates show that only about half the population with epilepsy was treated in 2001. A fact that should be investigated to find out if this is due to a lack of awareness or the stigma associated with this disorder or if there are any other factors responsible for the alarming treatment gap in these two cities. This result was definitely not due to the lack of medication as the final balance of the pharmacies was positive. However, in some cases the distribution flow was not continuous.

Campinas and São José do Rio Preto are two business centers in the region that have reasonable living conditions, infrastructure and healthcare systems. Therefore, poorer cities in Brazil with far more precarious conditions should present more critical figures.

The indirect measurement of the treatment gap is an extremely simplistic method for affirming the existence of a treatment gap as it does not take into account other variables such as the acqui- sition of AEDs from private pharmacies or data regarding patients who obtain good control with subdoses or those who need higher doses or use more than one drug nor those who use antiepileptic medication to treat other diseases such as carbamazepine to treat chronic pain and mood disorders or even the fact that the public health system covers only $70 \%$ of the population in the two cities. Nonetheless, it is universally accepted ${ }^{13-15}$ as a method for measuring the treatment gap and providing an estimate of how much should be invested in epidemiological studies on epilepsy, its control and the distribution of drugs.

Based on this panorama, epidemiological studies should be conducted to obtain more precise data so that treatment and distribution of medication is improved, expenses reduced and patients with epilepsy have a better quality of life.

Acknowledgements - We are grateful to the Health Secretariat - Campinas, Prof. Gastão Wagner de Souza Campos, Ex-Secretary of Health-Campinas and presently Executive Secretary of the Ministry of Health, the Health Secretariat - São José do Rio Preto, Prof. José Carlos Lopes (Cacau), Secretary of Health - São José do Rio Preto, and Mário Jabur Filho, special advisor to Secretary Cacau, for providing the data.

\section{REFERENCES}

1. Sander JW, Shorvon SD. Epidemiology of the epilepsies. J Neurol Neurosurg Psychiatry 1996;61:433-443.

2. Borges MA. Prevalência urbana da epilepsia: estudo populacional na cidade de São José do Rio Preto - Brasil. Tese, Faculdade de Medicina. São José do Rio Preto, 2002.

3. World Health Organization. Fact sheet 217: The global burden of mental and neurological problems. Geneva: WHO, 1999.

4. Salgado PC, Souza EA. [Quality of life in epilepsy and perception of seizures control]. Arq Neuropsiquiatr 2001;59:537-540.

5. Salgado PC, Souza EA. Impact of epilepsy at work: evaluation of quality of life. Arq Neuropsiquiatr 2002;60:442-445.

6. Borges MA, Pissolatti AF. [Migration in different sorts of work, unemployment and retirement of 81 epileptic patients: 3 years of ambulatory follow-up]. Arq Neuropsiquiatr 2000;58:107-111.

7. Kleinman A, Wang WZ, Li SC, et al. The social course of epilepsy: chronic illness as social experience in interior China. Soc Sci Med 1995;40:1319-1330.

8. Tekle-Haimanot R, Abebe M, Forsgren L, et al. Attitudes of rural people in central Ethiopia towards epilepsy. Soc Sci Med 1991;32:203-209.

9. Tekle-Haimanot R, Forsgren L, Gebre-Mariam A, et al. Attitudes of rural people in central Ethiopia towards leprosy and a brief comparison with observations on epilepsy. Lepr Rev 1992;63:157-168.

10. Shorvon SD, Farmer PJ. Epilepsy in developing countries: a review of epidemiological, sociocultural, and treatment aspects. Epilepsia 1988;29 (Suppl 1):S36-S54.

11. Leonardi M, Ustun TB. The global burden of epilepsy. Epilepsia 2002;43 (Suppl 6):S21-S25.

12. Li LM, Sander JW. [National demonstration project on epilepsy in Brazil]. Arq Neuropsiquiatr 2003;61:153-156.

13. Kale R. Global Campaign Against Epilepsy:the treatment gap. Epilepsia 2002;43 (Suppl 6):S31-S33.

14. Kale R. Epilepsy: problem solving in clinical practice. BMJ 2000;320:587A.

15. Kale R. Bringing epilepsy out of the shadows. BMJ 1997;315:2-3. 